\title{
An experimental investigation on the cylinder pressure of a biogas-diesel dual fuel engine
}

\author{
Liying Zhou, 2,a and Fuqiang Luo ${ }^{\text {2,b }}$ \\ ${ }^{1}$ School of Mechanical Engineering, Guiyang University, 103 Jianlong Road, Guiyang, 550005, \\ China
}

${ }^{2}$ School of Automobile and Traffic Engineering, Jiangsu University, 301 Xuefu Road, Zhenjiang, 212013, China

azhouliying0330@163.com, ${ }^{\mathrm{b}}$ luofq@ujs.edu.cn

\begin{abstract}
Keywords: Dual-Fuel Engine; Biogas; Combustion Characteristics; Cylinder Pressure
Abstract. By substituting a considerable amount of diesel fuel in diesel engines, combustible biogas is considered to be a renewable and promising alternative gaseous fuel. In this paper, biogas was made from agricultural and forestry residues with a gasifier. Its high quality was ensured by the process of cooling to obtain high density and condensation and by filtering to remove water vapor and tar. The dual fuel engine that was refitted from a diesel engine was fueled with biogas as the main fuel and diesel as the pilot fuel. In order to compare the combustion characteristics of biogas-diesel dual fuel engine and diesel engine, the cylinder pressure of dual fuel engine and diesel engine under load characteristics at different speeds was measured, and the characteristic combustion parameters such as combustion start timing, the maximum combustion pressure and the corresponding phase at different load and speed were analyzed. Meanwhile, the influence of different fuel supply advance angle on engine combustion process was measured and studied. The results show that the start timing of combustion of dual fuel engine is later than that of diesel engine, and that the maximum combustion pressure and the maximum pressure rise rate are higher than those of diesel engine at low speed and high load, but lower in all other conditions. Post combustion is more significant and exhaust temperature is higher under the biogas-diesel dual fuel operation at most operating conditions except for low speed and high load. The peak cylinder pressures of engines increase as fuel injection timing advances.
\end{abstract}

\section{Introduction}

The diesel engine is widely used because of higher thermal efficiency and lower exhaust emissions of unburned hydrocarbon $(\mathrm{HC})$, carbon monoxide $(\mathrm{CO})$ and carbon dioxide $\left(\mathrm{CO}_{2}\right)$ compared with those of gasoline engine. But the diesel engine emits a larger amount of oxides of nitrogen $\left(\mathrm{NO}_{\mathrm{X}}\right)$ and particulate matter (PM) that pose a significant threat to visibility and potential health. So, in oil crisis situations, the world especially has great interest in alternative fuels for energy saving and emission decreasing ${ }^{[1-4]}$.

Biogas, produced by the pyrolysis and gasification of cellulosic material (e.g., agricultural residues such as straw, rice husk, nutshell and maize residue, and the timber processing surplusage such as sawdust, shavings and scrap), is a renewable gaseous fuel and is very likely to serve as a hopeful alternative fuel in diesel engine by replacing a quantity of diesel fuel. As a combustible gas, the main components of biogas are $\mathrm{CO}$, hydrogen $\left(\mathrm{H}_{2}\right)$, methane $\left(\mathrm{CH}_{4}\right), \mathrm{CO}_{2}$ and nitrogen $\left(\mathrm{N}_{2}\right)$. Proper and massive utilization of biogas can contribute not only to less environmental pollution caused by biomass and secondary pollution but also to reduced engine dependency on petroleum resources ${ }^{[5-11]}$.

A biogas-diesel dual fuel engine can be easily refitted from a DI diesel engine. In dual fuel engines, biogas made from agricultural and forestry residues with a negative pressure downdraft gasifier is utilized as main fuel and is mixed with air before entering combustion chambers, and an amount of diesel is utilized as pilot fuel to ignite the inducted biogas, for the autoignition temperature of biogas is high. The dual fuel mode can contribute to environmental protection from two aspects: one is the consume of renewable fuel, the other is the decrease of $\mathrm{NO}_{\mathrm{X}}$ and $\mathrm{PM}$ emissions ${ }^{[12-15]}$. 
The performance of biogas-diesel dual fuel engine has been studied by some researchers. Nirendra $\mathrm{N}$. Mustafi et al. carried out an experimental research on the performance under biogas-diesel dual fuel operations. Their study showed higher net heat release rate, longer ignition delay, shorter combustion duration, lower $\mathrm{NO}_{\mathrm{X}}$ and $\mathrm{PM}$ emissions but significantly more $\mathrm{HC}$ emission compared with diesel fueling ${ }^{[16]}$. Phan Minh Duc et al. experimentally investigated the performance, diesel substitute and energy consume of a biogas-diesel dual fuel engine, and a conclusion was drawn that engine performance did not deteriorate, energy conversion efficiency decreased and the total fuel cost reduced $^{[17]}$. Seung Hyun Yoon et al. conducted experiments to study the emission and combustion performance of the engine fueled with biogas and diesel. Their study showed longer ignition delay and combustion duration, lower exhaust temperature, lower $\mathrm{NO}_{\mathrm{X}}$ emission and filter smoke number, and higher $\mathrm{HC}$ and $\mathrm{CO}$ emissions compared to diesel mode ${ }^{[18]}$. N. N. Mustafi et al. reported an experimental investigation of a biogas-diesel dual-fuel engine. The attained results revealed that the $\mathrm{PM}$ and $\mathrm{NO}_{\mathrm{X}}$ emissions were much smaller than those of diesel operation ${ }^{[19]}$.

The combustion process has great effect on power, economy and emission performance of engines, and there is a great deal of research on combustion process of diesel engines. But there is little report about the change law of characteristic parameters of combustion process at operation range, and the combustion characteristics of biogas-diesel dual fuel operation have rarely been reported.

Our work aims to analyze the combustion characteristics of biogas-diesel dual fuel engine. For this reason, in this work, a dual fuel engine refitted from a diesel engine was fueled with combustible biogas as main fuel and diesel as pilot fuel. For comparison purposes, the combustion characteristics of biogas-diesel dual fuel engine and diesel engine were analyzed, and the influence of the change of fuel injection timing on combustion process of engines was measured and studied.

\section{Biogas-diesel dual fuel engine and experimental setup}

The schematic diagram of biogas-diesel dual fuel engine experimental setup is shown in Fig.1. The biogas-diesel dual fuel engine was operated with biogas-diesel dual fuels and pure diesel fuel, respectively. The base engine for this research work was a water-cooled, single-cylinder, four-stroke, direct injection diesel engine, and the engine technical characteristics and major specifications are given in Table1. Combustible biogas was made from agricultural and forestry residues with a gasifier. After being cooled and filtered, biogas is utilized as main fuel. 
Table 1. Test engine characteristics and specifications.

\begin{tabular}{|c|c|}
\hline Engine type & Horizontal type, single-cylinder, four-stroke, water-cooled \\
\hline Bore $\times$ Stroke & $115 \times 115 \mathrm{~mm}$ \\
\hline Displacement & $1194 \mathrm{~cm}^{3}$ \\
\hline Rated power & $14.7 \mathrm{~kW}$ at $2200 \mathrm{rpm}$ \\
\hline Maximum torque & $71.46 \mathrm{Nm}$ at $1650 \mathrm{rpm}$ \\
\hline Compression ratio & $16 \pm 1$ \\
\hline Mean effective pressure & $0.67154 \mathrm{MPa}$ \\
\hline Fuel injection timing & $21^{\circ} \mathrm{CA} \mathrm{BTDC}($ before top dead center) \\
\hline Nozzle opening pressure & $186.3+4.9$ bar \\
\hline Specific fuel consumption & $\leq 242.1 \mathrm{~g} /(\mathrm{kW} \cdot \mathrm{h})$ \\
\hline The number of nozzle hole $\times$ Nozzle hole diameter & $4 \times 0.32 \mathrm{~mm}$ \\
\hline Inlet valve open & $12^{\circ} \mathrm{CA} \mathrm{BTDC}$ \\
\hline Inlet valve close & $38^{\circ} \mathrm{CA}$ ABDC(after bottom dead center) \\
\hline Exhaust valve open & $55^{\circ} \mathrm{CA} \mathrm{BBDC}$ (before bottom dead center) \\
\hline Exhaust valve close & $12^{\circ} \mathrm{CA}$ ATDC(after top dead center) \\
\hline
\end{tabular}

The combustion process of biogas-diesel dual fuel engine and diesel engine was measured by self-developed measurement and analysis system for working process of diesel engine ${ }^{[20]}$. The cylinder pressure was measured with a water-cooled piezoelectric pressure sensor, flush mounted to the cylinder head surface. The signals measured by the sensor were amplified by a charge amplifier. After being amplified by the charge amplifier, charge signals generated by the piezoelectric pressure transducer were converted through $\mathrm{AD}$ conversion, and then stored in a computer for sampling and processing. The sampling interval of our measurement and analysis system was set to $0.25^{\circ} \mathrm{crank}$ angle (CA), $0.5^{\circ} \mathrm{CA}$ and $1^{\circ} \mathrm{CA}$. The characteristic parameters of combustion process such as the timing of combustion, maximum combustion pressure, maximum pressure rise rate and corresponding phases were obtained $^{[4,21,22]}$. 


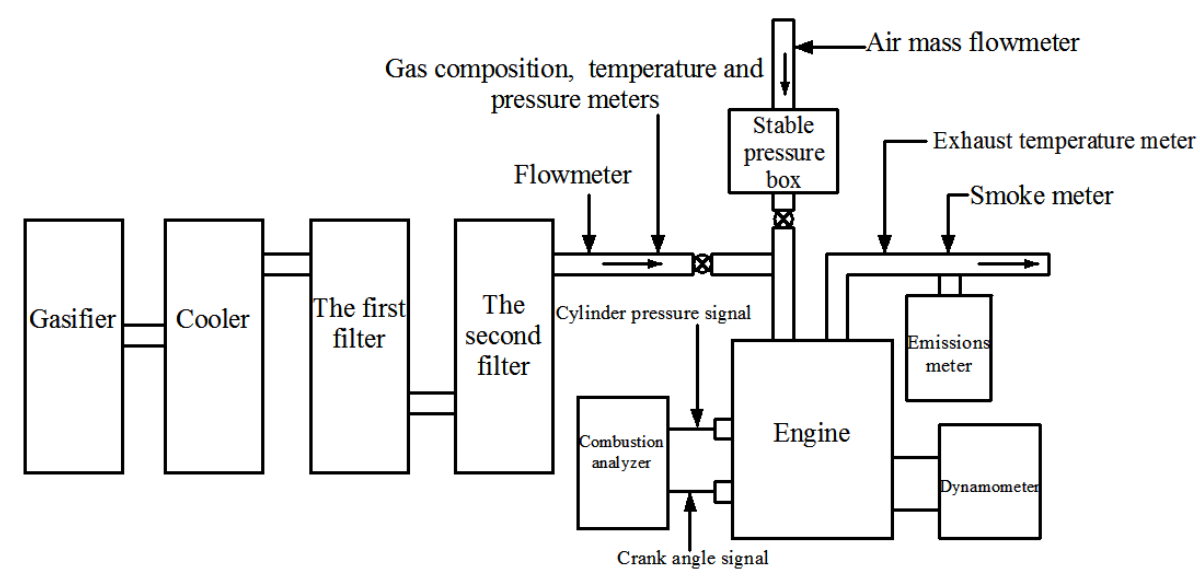

Fig. 1. Schematic diagram of biogas-diesel dual fuel engine experimental setup.

The gasifier is of negative pressure downdraft type. Biomass material is fed from the feed inlet of silo, and air as an oxidant flows in the downward direction into gasification chamber due to negative pressure caused by engine intake. Combustible biogas is the product of pyrolysis-gasification reaction between biomass material and air.

Due to its higher temperature and the existing water vapor and tar, the high quality of this product gas is ensured by cooling to obtain high density and condensation and by filtering to remove water vapor and tar. A partition wall type heat exchanger is used to cool high temperature gas down to below $30^{\circ} \mathrm{C}$. The contents of tar and dust in cooled gas are controlled by two-stage spin-flow filtering to satisfy operating requirements of dual fuel engine.

Water sealing connection between gasifier and cooler is utilized not only to perform reliable sealing but also to ensure safe operation by automatic relief protection when the gas pressure becomes excessively high.

In the experiment, the gasifier was ignited first, and the silo was filled with biomass material when it started to produce biogas. With gas valve shut off, this engine was fired with pure diesel. When desired oil and water temperatures of the engine were reached, this engine was switched into dual fuel mode through gradually opening the valve to full open. Diesel as pilot fuel accounted for about $20 \%$ of the total fuel quantity at rated condition.

\section{Measurement and analysis of combustion process of the biogas-diesel dual fuel engine}

The cylinder pressures under load sweep at the speed of $1400 \mathrm{rpm}$ and $2200 \mathrm{rpm}$ were measured respectively, and the changing trends of the characteristic parameters of combustion process were analyzed. Combustion processes under normal diesel operation and dual fuel operation with different fuel injection timing were also measured and studied.

Figs.2 5 show the cylinder pressures at the speed of 1400rpm and 2200rpm at different loads under normal diesel operation and dual fuel operation, respectively. Figs.6 9 show the cylinder pressures under the same speed and load as well as operation modes as Figs.2 5 except for the fuel injection timing being $3^{\circ} \mathrm{CA}$ earlier. 


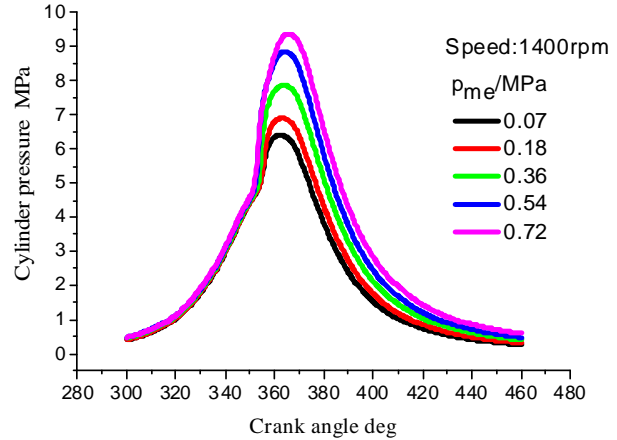

Fig. 2. Cylinder pressure of diesel engine at different loads.

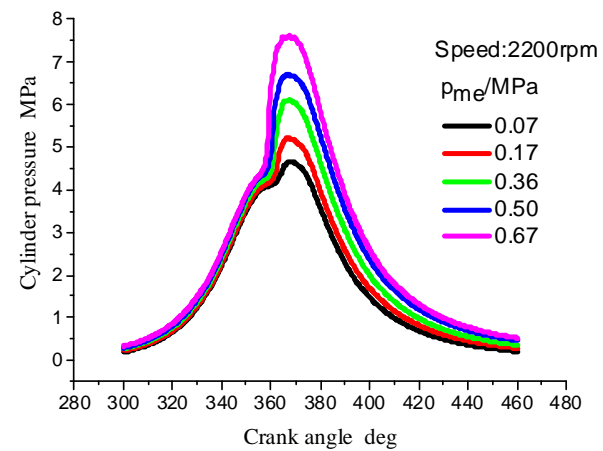

Fig. 4. Cylinder pressure of diesel engine at different loads.

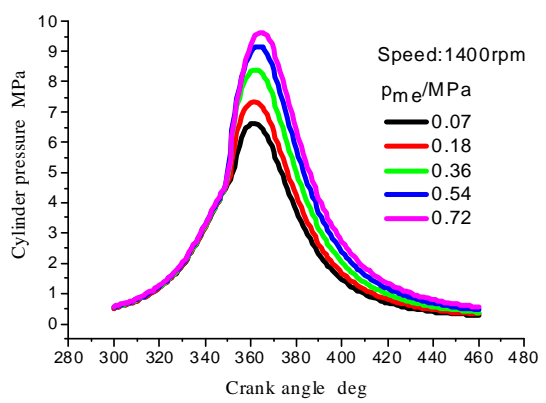

Fig. 6. Cylinder pressure of diesel engine at different loads with fuel injection timing $3^{\circ} \mathrm{CA}$ earlier.

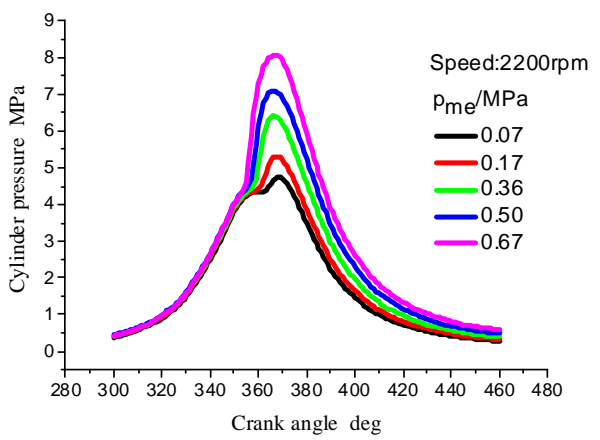

Fig. 8. Cylinder pressure of diesel engine at different loads with fuel injection timing $3^{\circ} \mathrm{CA}$ earlier.

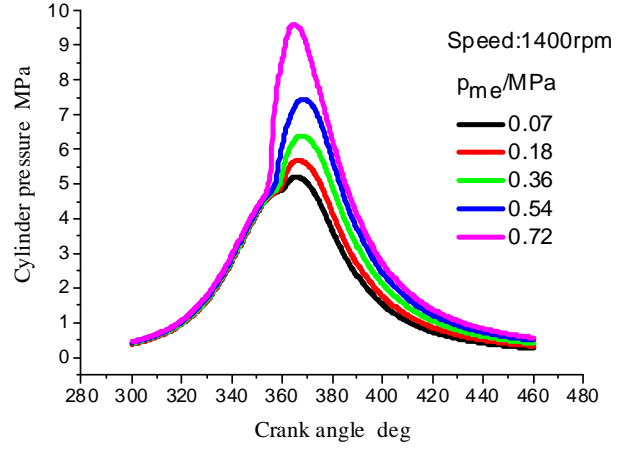

Fig. 3. Cylinder pressure of dual-fuel engine at different loads.

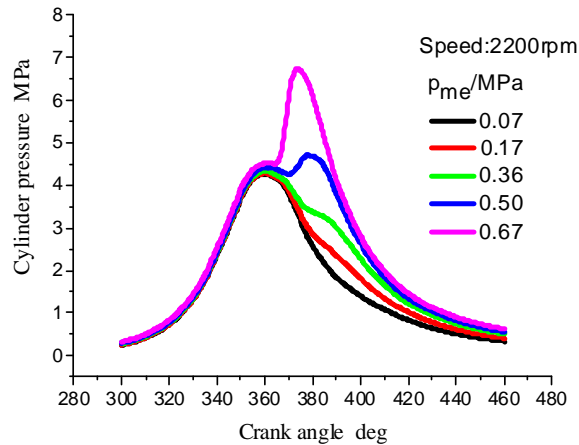

Fig. 5. Cylinder pressure of dual-fuel engine at different loads.

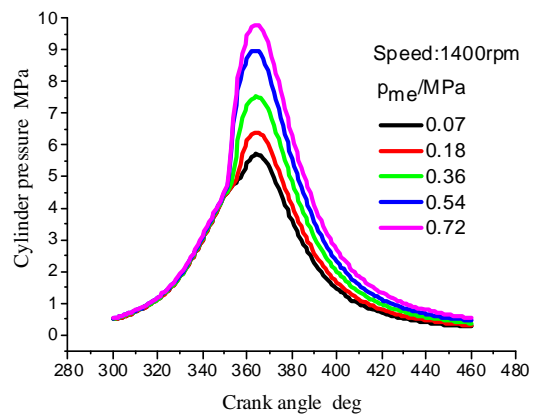

Fig. 7. Cylinder pressure of dual-fuel engine at different loads with fuel injection timing $3^{\circ} \mathrm{CA}$ earlier.

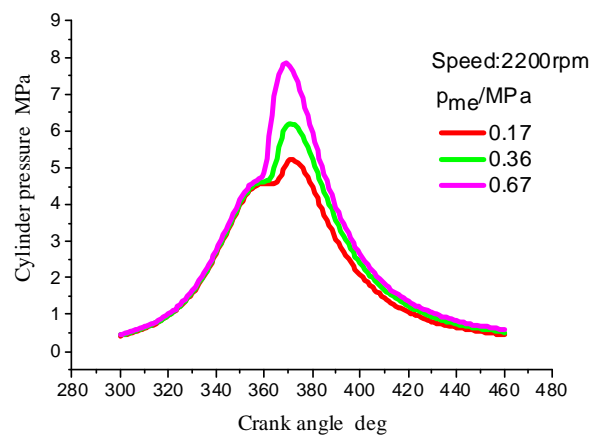

Fig. 9. Cylinder pressure of dual-fuel engine at different loads with fuel injection timing $3^{\circ} \mathrm{CA}$ earlier.

It can be seen that the cylinder pressure and the pressure rise rate are lower compared to diesel mode. Furthermore, post combustion is more significant under dual fuel operation and at higher speed $^{[1]}$. While at low speed and higher load, the cylinder pressure and the pressure rise rate are higher than those under diesel operation.

These figures show that the maximum combustion pressure decreases, the combustion start time delays, and the phase of the maximum combustion pressure advances with the load and fuel quantity 
decreasing at constant engine speeds. As the engine speed decreases while the load is the same, the combustion start time advances, the maximum combustion pressure increases and its corresponding phase advances. This is due to the advanced fuel injection timing ${ }^{[12]}$.

As shown in these figures, in dual fuel operation the combustion start time is relatively later for the same injection timing, the maximum combustion pressure is lower and corresponding phase is later except at low speed and high load condition, and the pressure rise rate is lower except at high speed and light load condition.

For the dual fuel operation, oxygen concentration in cylinder is lower and the specific heat of the mixture is larger than that of air. The reason is that biogas provided during intake stroke substituted an amount of inlet air. In addition, the biogas contains inert gas such as $\mathrm{CO}_{2}$ and $\mathrm{N}_{2}{ }^{[5]}$. Moreover, the ignition delay period is prolonged, the cylinder temperature increases slowly, and thus burning rate decreases compared to diesel mode. This is because of the decrease of fuel injection quantity, lower injection pressure and poorer atomization, which leads to less combustible gas mixture and lower concentration during the period of ignition delay. Thus, in most operating region during the dual fuel operation, the cylinder pressure is lower, the phase of the maximum combustion pressure is delayed, the post combustion is more, and the exhaust temperature is higher ${ }^{[18]}$.

On the contrary, the maximum combustion pressure and pressure rise rate were observed to be higher at lower engine speeds and high loads in dual fuel combustion compared to neat diesel combustion. The reason is that the fuel injection timing is earlier and the ignition delay is increased at low speeds, thus there is more gaseous mixture burned before the top dead center after ignition.

It was also noticed that the maximum combustion pressure is lower than the compress pressure at high speed and low load in dual fuel operation. This is mainly because the ignition is after top dead center, meanwhile, the amount of combustible mixture is less.

It can be seen from these figures that the phases of ignition and maximum combustion pressure are advanced, and the maximum combustion pressure is increased with the fuel injection timing advancing because of longer ignition delay caused by advanced fuel injection timing and a larger amount of combustible mixture formed during rapid combustion period. The change trend of combustion characteristics is almost the same as that of original neat diesel and dual fuel combustions. But at low speed and high load the region in which the maximum combustion pressure increases compared to neat diesel mode is enlarged. Meanwhile, at high speed and low load the ignition occurs before top dead center and the corresponding phase of the maximum combustion pressure is advanced.

\section{Conclusion}

The agricultural and forestry residues are gasified in a miniature gasifier to produce combustible biogas. This product (biogas) is used as the main fuel of a biogas-diesel dual fuel engine. A comparative study of the combustion characteristics of both the dual fuel engine and the diesel engine has been performed. The results show that the cylinder pressure and the maximum pressure rise rate are lower, post combustion is more significant, and exhaust temperature is higher under the biogas-diesel operations at most operating condition except at low speed and high load, at which the maximum combustion pressure and maximum pressure rise rate are higher. This is mainly because of the lower oxygen concentration in cylinder, larger specific heat of the mixture and slow combustion rate. The cylinder pressure in both diesel and dual fuel combustions increases when the fuel injection timing advances.

\section{Acknowledgements}

This research is funded by the Science and Technology Foundation of Guizhou Province (20147186), Scientific Research Innovation Foundation for Graduate Students of Jiangsu Province (CXLX13_654) and a Project Supported by the Priority Academic Program Development of Jiangsu High Education Institutions. 


\section{References}

[1] T. Lakshmanan and G. Nagarajan: Experimental investigation of timed manifold injection of acetylene in direct injection diesel engine in dual fuel mode, Energy 35, 3172-3178(2010).

[2] Violeta Makareviciene, Egle Sendzikiene, Saugirdas Pukalska, Alfredas Rimkus and Ricardas Vegneris: Performance and emission characteristics of biogas used in diesel engine, Energy Conversion and Management 75, 224-233(2013).

[3] Yoge Jerônimo Ramos da Costa, Antonio Gilson Barbosa de Lima, Celso Rosendo Bezerra Filho and Laerte de Araujo Lima: Energetic and exergetic analyses of a dual-fuel diesel engine, Renewable and Sustainable Energy Reviews 16, 4651-4660(2012).

[4] N. R. Banapurmath, P. G. Tewari, V. S. Yaliwal, S. Kambalimath and Y. H. Hasavarajappa: Combustion characteristics of a 4-stroke CI engine operated on honge oil, neem and rice bran oils when directly injected and dual fuelled with producer gas induction, Renewable Energy 34, 1877-1884 (2009).

[5] Mark Maizonnasse, Jean-Sébastien Piante, David Oh and Claude B. Laflamme: Investigation of the degradation of a low-cost untreated biogas engine using preheated biogas with phase separation for electric power generation, Renewable Energy 55, 501-513 (2013).

[6] Mirko Morini, Michele Pinelli and Mauro Venturini: Analysis of biogas compression system dynamics, Applied Energy 86, 2466-2475 (2009).

[7] Iván Darío Bedoya, Andrés Amell Arrieta and Francisco Javier Cadavid: Effect of mixing system and pilot fuel quality on diesel-biogas dual fuel engine performance, Bioresource Technology 100, 6624-6629 (2009).

[8] B. B. Sahoo, N. Sahoo and U. K. Saha: Effect of engine parameters and type of gaseous fuel on the performance of dual-fuel gas diesel engines-A critical review, Renewable Sustainable Energy Rev. 13, 1151-1184 (2009).

[9] A. S. Ramadhas, S. Jayaraj and C. Muraleedharan: Dual fuel mode operation in diesel engines using renewable fuels: Rubber seed oil and coir-pith producer gas, Renewable Energy 33, 2077-2083 (2008).

[10] G. Sridhar, P. J. Paul and H. S. Mukunda: Biomass derived producer gas as a reciprocating engine fuel-an experimental analysis, Biomass Bioenergy 21, 61-72 (2001).

[11] Nutthapong Tonkunya and Tanakorn Wongwuttanasatian: Utilization of biogas-diesel mixture as fuel in a fertilizer pelletising machine for reduction of greenhouse gas emission in small farms, Energy for Sustainable Development 17, 240-244 (2013).

[12] Karen Cacua, Andrés Amell and Francisco Cadavid: Effects of oxygen enriched air on the operation and performance of a diesel-biogas dual fuel engine, Biomass and Bioenergy 45, 159-167 (2012).

[13] N. Tippayawong, A. Promwungkwa and P. Rerkkriangkrai: Long-term operation of a small biogas/diesel dual-fuel engine for on-farm electricity generation, Biosystems Engineering 98, 26-32 (2007).

[14] R.G. Papagiannakis, D.T. Hountalas and C.D. Rakopoulos: Theoretical study of the effects of pilot fuel quantity and its injection timing on the performance and emissions of a dual fuel diesel engine, Energy Conversion and Management 48, 2951-2961 (2007).

[15] S. Swami Nathan, J.M. Mallikarjuna and A. Ramesh: An experimental study of the biogas-diesel HCCI mode of engine operation, Energy Conversion and Management 51, 1347-1353 (2010).

[16] Nirendra N. Mustafi, Robert R. Raine and Sebastian Verhelst: Combustion and emissions characteristics of a dual fuel engine operated on alternative gaseous fuels, Fuel 109, 669-678 (2013).

[17] Phan Minh Duc and Kanit Wattanavichien: Study on biogas premixed charge diesel dual fuelled engine, Energy Conversion and Management 48, 2286-2308 (2007).

[18] Seung Hyun Yoon and Chang Sik Lee: Experimental investigation on the combustion and exhaust emission characteristics of biogas-biodiesel dual-fuel combustion in a CI engine, Fuel Processing Technology 92, 992-1000 (2011). 
[19] N.N. mustafi and R.R. Raine: A study of the emission of a dual fuel engine operating with alternative gaseous fuels, SAE. 2008-01-1394, 2008.

[20] Fuqiang Luo and Zongying Gao: A measurement and analysis system for instantaneous speed and working processes of diesel engine under transient conditions, Chinese Internal Combustion Engine Engineering 17, 13-17 (1996).

[21] C.D. Rakopoulos, D.C. Rakopoulos, E.G. Giakoumis and A.M. Dimaratos: Investigation of the combustion of neat cottonseed oil or its neat bio-diesel in a HSDI diesel engine by experimental heat release and statistical analyses, Fuel 89, 3814-3826 (2010).

[22] N.R. Banapurmatha, P.G. Tewari and R.S. Hosmath: Experimental investigations of a four-stroke single cylinder direct injection diesel engine operated on dual fuel mode with producer gas as inducted fuel and Honge oil and its methyl ester (HOME) as injected fuels, Renewable Energy 33, 2007-2018 (2008). 